\title{
Evaluation of tumor M2-pyruvate kinase (Tumor M2-PK) as a biomarker for pancreatic cancer
}

\author{
Indika A. Bandara' ${ }^{1}$, Minas Baltatzis ${ }^{1}$, Sudip Sanyal ${ }^{1}$ and Ajith K. Siriwardena ${ }^{1,2^{*}}$
}

\begin{abstract}
Background: Expression of the dimeric M2 isoenzyme of pyruvate kinase, termed Tumor M2-PK, is increased in some human cancers. This study evaluates the potential role of pre-operative Tumor M2-PK as a marker of prognosis in patients with pancreatic malignancy.

Methods: Seventy-three consecutive patients with a clinical diagnosis of pancreatic or peri-ampullary cancer were enrolled. Their median (range) age was 66 (23-83) years. Pre-operative samples of venous blood were taken for analysis of Tumor M2-PK. The full study protocol was approved by the North West Research Ethics Committee (protocol number 06/MRE08/69).

Results: The mean (standard deviation) plasma Tumor M2-PK in pancreatic/peri-ampullary malignancy was 60.3 (106.5) $\mathrm{U} / \mathrm{ml}$ and $22 \mathrm{U} / \mathrm{ml}(\mathrm{SD}: 12 \mathrm{U} / \mathrm{ml}$ ) in benign disease $(p<0.001)$. Multivariate Cox regression analysis showed that Tumor M2-PK (> $27 \mathrm{U} / \mathrm{mL}$ ), Ca19-9 (> $39 \mathrm{U} / \mathrm{ml})$, resection status, and disease stage were associated with poorer survival. Tumor M2-PK values greater than $27 \mathrm{U} / \mathrm{ml}$ were associated with inferior survival compared to those with lower values (hazard ratio 2.049, significantly increased risk of death, $p=0.042$ ).

Conclusion: This preliminary study shows that an elevated level of Tumor M2-PK (with a cutoff threshold of $27 \mathrm{U} / \mathrm{mL}$ ) measured pre-operatively is associated with poorer prognosis in patients with pancreatic and peri-ampullary cancer.
\end{abstract}

Keywords: Pancreatic cancer, Cancer prognosis, Tumor M2-PK

\section{Background}

In mammalian tissues, there are four different molecular isoforms of pyruvate kinase [1-3]. The dimeric M2 isoenzyme is over-expressed in a range of cancers [4-9]. Using an enzyme-linked immunosorbent assay (ELISA) assay, we previously evaluated the role of tumor M2pyruvate kinase as a diagnostic test for pancreatic cancer [10]. The mean (SD [standard deviation]) plasma Tumor M2-PK level for patients with histologically proven malignancy was $40.5(26.4) \mathrm{U} / \mathrm{mL}$ and for non-cancer patients, $29.9(20.9) \mathrm{U} / \mathrm{mL}$ (Mann-Whitney $U=1163$, $p=0.006$ ) [10]. Tumor M2-pyruvate kinase had an area under the curve (AUC) of 0.623 on receiver operating characteristic curve analysis and at an optimal cutoff of

\footnotetext{
* Correspondence: a.siriwardena@btinternet.com
${ }^{1}$ Regional Hepato-Pancreato-Biliary Unit, Manchester Royal Infirmary, Oxford

* Correspondence: a.siriwardena@btinternet.com
${ }^{1}$ Regional Hepato-Pancreato-Biliary Unit, Manchester Royal Infirmary, Oxford Road, Manchester M13 9WL, UK

${ }^{2}$ Faculty of Biology, Medicine and Health, University of Manchester, Manchester, UK
}

\section{Methods \\ Study design}

This is a single center, prospective cohort study comparing pre-operative plasma Tumor M2-PK measurement

$27 \mathrm{U} / \mathrm{mL}$, sensitivity was $66 \%$, and specificity was $58 \%$. On multivariate Cox regression modeling, elevated Tumor M2-PK (> $27 \mathrm{U} / \mathrm{mL}$ ) was strongly correlated with the subsequent finding of poorly differentiated cancer and/or metastatic disease and strongly predicted adverse survival on Kaplan-Meier analysis. The diagnostic accuracy of Tumor M2-PK was not affected by jaundice. These findings suggest that although the test is unlikely to be of value as a diagnostic aid, there may be a potential niche as an indicator of prognosis. The present study assesses the prognostic value of Tumor M2-PK in pancreatic and peri-ampullary cancer. 
to outcome in patients with suspected pancreatic/periampullary cancer.

\section{Setting}

The study was conducted in the regional Hepatobiliary and Pancreatic (HPB) cancer service of the Manchester Royal Infirmary. This is a tertiary HPB service treating a predominantly urban conurbation of 3.2 million.

\section{Patients}

Patients referred with a clinical diagnosis of pancreatic or peri-ampullary cancer between May 2011 and February 2014 constituted the study population. Patients being staged for resection of pancreatic tumors were included if they were older than 18 years of age and if there was no evidence of metastatic disease. Only patients able to give full informed consent were included. Exclusion criteria included inability to give informed consent, age younger than 18 years and a histologically confirmed concurrent non-pancreatic malignancy or a subsequent diagnosis of a non-pancreatic malignancy during the follow-up period. Those who were confirmed to have malignancy from preoperative cytology as well as patients with only a clinical/ radiological diagnosis of pancreatic cancer confirmed by the Multidisciplinary Team (MDT) were included in the survival analysis, whereas patients with histologically confirmed benign lesions after resection were excluded. Seventy-three consecutive patients with a clinical diagnosis of pancreatic or peri-ampullary cancer were enrolled. Their median (range) age was 66 (23-83) years. Eight patients $(11 \%)$ were diagnosed as having unresectable disease pre-operatively during work-up and did not undergo surgical treatment. Of the 65 ( $89 \%$ of the entire cohort) who underwent surgical treatment, 55 had resection of their tumor and 10 had palliative non-resectional treatment. Nine patients (12\%) undergoing resection of suspected malignant disease had benign histology on resection and were excluded from the survival analysis.

\section{Sample collection, storage, and biochemical assays}

Five milliliter of whole venous blood was collected into an EDTA (ethylene diamine tetra-acetic acid) bottle at room temperature. The sample was spun for $10 \mathrm{~min}$ at $3000 \mathrm{rpm}$ within $12 \mathrm{~h}$ of collection. Plasma was separated into two aliquots in $\mathrm{Z} 5$ screw top tubes and stored immediately at $-80{ }^{\circ} \mathrm{C}$. The final batch analysis for Tumor M2-PK was performed at the ScheBo Biotech laboratory (Geissen, Germany) in compliance with previously published protocols [10]. CA 19-9 analysis for this study was undertaken as part of routine clinical care by the National Health Service reference laboratory at the Christie Hospital, Manchester.

\section{Data collection}

Electronic case report forms were used to collect information on the following: demographic data: Age, gender, smoking status, co-morbidities; clinical data on presentation, results of hematological, biochemical, radiological, cytological investigations; and operative detail in those patients undergoing surgery and histology together with peri-operative outcome, survival, and follow-up data.

\section{Data analysis}

The Statistical Package for the Social Sciences version 21.0 (IBM Corp; IBM SPSS Statistics for Windows, Version 21.0, Armonk, NY, USA) was utilized for statistical analysis. Receiver operator curves were generated for Tumor M2-PK. Multivariate Cox regression was used for survival analyses. The Kolmogorov-Smirnov test was used to assess for parametric (normal) distribution and two sample comparisons were by $t$ test. A probability of less than 0.05 was considered statistically significant.

\section{Ethics committee approval}

The study was approved by the North West Regional Ethics Committee (reference number 10/H1014/86). All patients gave their written informed consent for participation.

\section{Results}

Patients

Demographic and disease profiles are seen in Table 1.

\section{Plasma Tumor M2-PK and CA 19-9}

In patients with pancreatic/peri-ampullary cancer, Tumor M2-PK 60.3 (SD 106.5) U/ml compared to 22 (SD 12) $\mathrm{U} / \mathrm{ml}(\mathrm{SD} 12 \mathrm{U} / \mathrm{ml})$ in patients without malignancy $(p<0.001)$. Serum Ca19-9 was 1750 (SD 4817) $\mathrm{U} / \mathrm{ml}$ in those with pancreatic/peri-ampullary cancer and $16(12) \mathrm{U} / \mathrm{ml}$ in patients without malignancy $(p=0.004)$.

\section{Tumor M2-PK as a predictor of survival}

Tumor M2-PK (> $27 \mathrm{U} / \mathrm{mL})$, Ca19-9 (39 U/ml), resection status (resection or not), and advanced stage (stages III and IV) correlated with inferior survival. Patients with Tumor M2-PK higher than $27 \mathrm{U} / \mathrm{ml}$ had worse prognosis than those with lower values (hazard ratio 2.049 , significantly increased risk of death, $p=0.042$ ). Figure 1 shows the Kaplan-Meier survival curves for Tumor M2-PK above and below the cutoff level. Figure 2 shows the Kaplan-Meier curves in the subgroup of patients who underwent surgical resection. 
Table 1 Demographic and disease profile

\begin{tabular}{|c|c|}
\hline Age (median--range) & $66(23-83)$ \\
\hline Gender & $\begin{array}{l}\text { Male } 52 \text { (71\%) } \\
\text { Female } 21 \\
(29 \%)\end{array}$ \\
\hline \multicolumn{2}{|l|}{ Management } \\
\hline Surgical treatment & 65 (89\%) \\
\hline Resection & 55 \\
\hline Pancreaticoduodenectomy & 47 \\
\hline Distal pancreatectomy + splenectomy & 5 \\
\hline Total pancreatectomy & 2 \\
\hline Central pancreatectomy & 1 \\
\hline No resection & 10 \\
\hline Palliative procedures & 8 \\
\hline Intraoperative biopsy only & 2 \\
\hline No surgical treatment & $8(11 \%)$ \\
\hline \multicolumn{2}{|l|}{ Histology of resected specimen } \\
\hline Malignant & $46(63 \%)$ \\
\hline Pancreatic ductal adenocarcinoma & 18 \\
\hline Ampullary adenocarcinoma & 15 \\
\hline Neuroendocrine tumor & 6 \\
\hline Distal bile duct cholangiocarcinoma & 4 \\
\hline Duodenal adenocarcinoma & 2 \\
\hline Pancreatic adenosquamous carcinoma & 1 \\
\hline Benign & $9(12 \%)$ \\
\hline Groove pancreatitis & 2 \\
\hline Chronic pancreatitis & 2 \\
\hline Ampullary tubulovillous adenoma & 2 \\
\hline Mucinous neoplasm & 1 \\
\hline Serous cystadenoma & 1 \\
\hline Solid pseudopapillary tumor & 1 \\
\hline Histology/cytology from biopsy & $18(25 \%)$ \\
\hline Pancreatic ductal/ampullary adenocarcinoma & 8 \\
\hline Neuroendocrine tumor & 1 \\
\hline Adenocarcinoma (frozen section) & 5 \\
\hline $\begin{array}{l}\text { Histology not confirmed (clinical/radiological } \\
\text { diagnosis) }\end{array}$ & 4 \\
\hline \multicolumn{2}{|l|}{ Cancer differentiation $^{a}$} \\
\hline Well and moderately differentiated & 34 \\
\hline Poorly differentiated & 16 \\
\hline \multicolumn{2}{|l|}{ Resection margin ${ }^{\mathrm{b}}$} \\
\hline RO & 18 \\
\hline R1 & 28 \\
\hline
\end{tabular}

$R O$ complete histological resection with at least $1-\mathrm{mm}$ clear resection margin. $R 1$ tumor reaches surgical resection margin

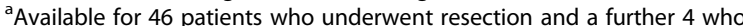
underwent biopsy

${ }^{\mathrm{b}}$ Applies only to patients undergoing surgical resection for cancer

The values in italics denote statistical significance

\section{Pre-operative Tumor M2-PK as predictor of advanced stage}

Two separate ROC curve analyses were performed to assess sensitivity and specificity of Tumor M2-PK in predicting advanced disease stage (III and IV) and tumor unresectability, respectively. Tumor M2-PK at a cutoff value of $25.37 \mathrm{U} / \mathrm{ml}$ had a sensitivity of $85 \%$ and specificity of $43 \%$ in predicting stage III/IV disease (Table 2). The negative predictive value (NPV) was $74 \%$ and positive predictive value (PPV) 60\%. Area under curve (AUC) was 0.583. Tumor M2-PK cutoff value of $27.82 \mathrm{U} / \mathrm{ml}$ had a sensitivity of $72 \%$ and specificity of $42 \%$ in predicting unresectability. AUC was 0.514, NPV $=60 \%$, and PPV $=55 \%$.

\section{Discussion}

This study has re-evaluated plasma Tumor M2-PK as a potential marker of prognosis in patients with pancreatic and peri-ampullary cancer. As the dimeric M2 isoform detected by the assay is overexpressed in cancer, the hypothesis that patients with a poorer prognosis cancer are more likely to have disseminated disease and thus more sources of Tumor M2-PK production seems reasonable $[11,12]$. Our previous study showed that Tumor M2-PK, unlike CA 19-9 was not affected by preoperative jaundice but was insufficiently accurate for use as a diagnostic test. An interesting finding of that study was that there was differential survival according to preoperative Tumor M2-PK with patients having values above $27 \mathrm{U} / \mathrm{mL}$ having worse outcome compared to those with values lower than this. The present study sets out to explore this phenomenon.

In relation to the present study, although this was carried out in a regional hepato-pancreato-biliary center, it is acknowledged that the sample number is small, that during the period of the study, there was a surprisingly high proportion of patients undergoing resection for suspected malignancy with a final diagnosis of noncancer and a small proportion of patients included in the analyses had clinical and radiological diagnoses of pancreatic malignancy but did not have tissue confirmation of cancer. A protocol which included serial postoperative measurement would also have helped to assess whether resection of macroscopic disease with clear resection margins was associated with a fall in Tumor M2-PK.

Accepting these limitations, there are some important findings from this study. First, the study confirms again that Tumor M2-PK is elevated in patients with pancreatic and peri-ampullary malignancy compared to patients without cancer. Although our previous study sought to utilize the diagnostic potential of this test by using it in combination with CA 19-9, current information suggests that Tumor M2-PK is not sufficiently accurate for use as a diagnostic test. When measured 


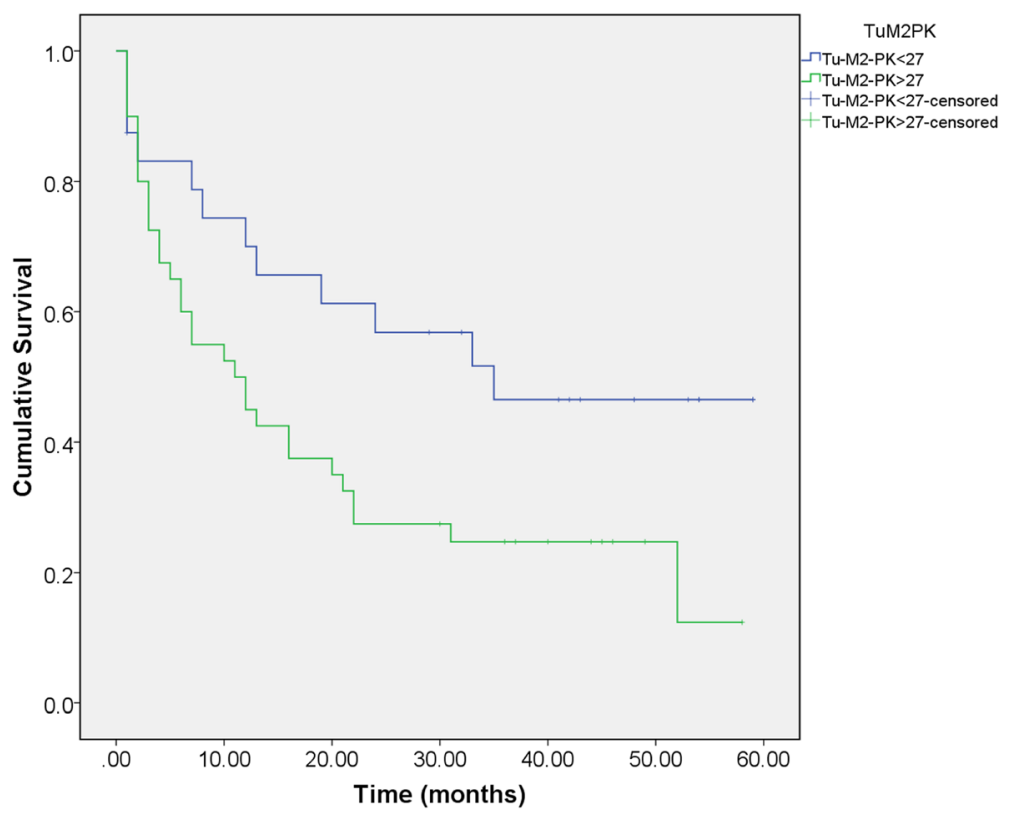

Fig. 1 Kaplan-Meier survival plot. Survival in months from the time of presentation according to Tumor M2-PK greater or lower than $27 \mathrm{U} / \mathrm{mL}$

pre-operatively, the test does appear to have discriminant value in terms of predicting prognosis with values above $27 \mathrm{U} / \mathrm{mL}$ being associated with shortened survival. Currently, the EDTA plasma test for Tumor M2PK is undertaken as an immune-assay of stored batched samples. If further studies indicate a viable clinical role for this assay, single-sample analytic techniques will be required.
Both the present study and our previous report are relatively small studies, and thus, the findings are insufficiently robust to recommend general adoption of the test without further confirmation. Pooling of the results of the two studies would be unwise as the samples were from widely disparate time periods. Other studies do also support an association between elevated Tumor M2-PK and poor prognosis [13, 14].

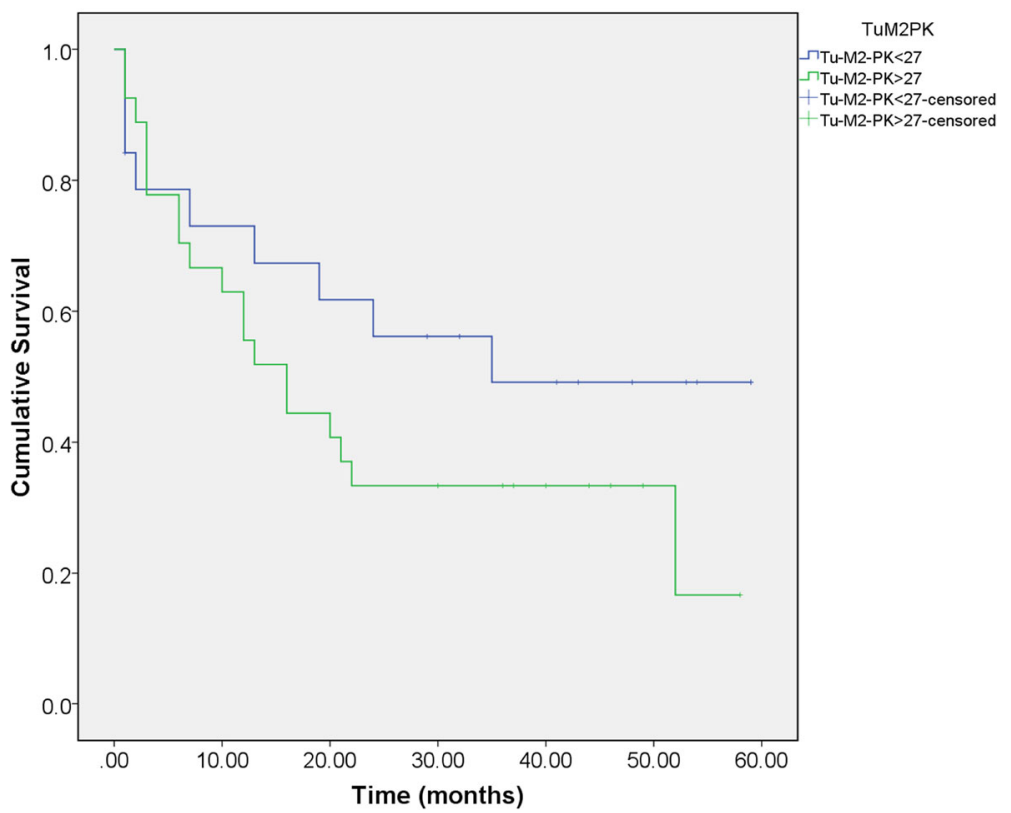

Fig. 2 Kaplan-Meier survival plot for patients undergoing surgical resection 
Table 2 Exploratory survival analysis

\begin{tabular}{|c|c|c|c|c|c|c|}
\hline & $b$ & SE & Wald & $d F$ & Sig & $\begin{array}{l}\operatorname{Exp}(B) \\
\text { (hazard ratio) }\end{array}$ \\
\hline \multicolumn{7}{|l|}{ Base model } \\
\hline Age & 0.010 & 0.014 & 0.563 & 1 & 0.453 & 1.010 \\
\hline Gender & -0.167 & 0.327 & 0.261 & 1 & 0.609 & 0.846 \\
\hline \multicolumn{7}{|c|}{ Incremental model: tumor M2-PK > $27 \mathrm{U} / \mathrm{mL}$} \\
\hline Age & 0.004 & 0.015 & 0.076 & 1 & 0.782 & 1.004 \\
\hline Gender & -0.221 & 0.329 & 0.452 & 1 & 0.501 & 0.802 \\
\hline Tumor M2-PK > $27 \mathrm{U} / \mathrm{ml}$ & 0.718 & 0.353 & 4.132 & 1 & 0.042 & 2.049 \\
\hline \multicolumn{7}{|c|}{ Incremental model: Ca 19-9> 39} \\
\hline Age & 0.010 & 0.014 & 0.472 & 1 & 0.492 & 1.010 \\
\hline Gender & -0.515 & 0.351 & 2.153 & 1 & 0.142 & 0.598 \\
\hline Ca 19-9> 39 & 1.081 & 0.345 & 9.821 & 1 & 0.002 & 2.949 \\
\hline \multicolumn{7}{|c|}{ Incremental model: resection } \\
\hline Age & 0.013 & 0.014 & 0.862 & 1 & 0.353 & 1.013 \\
\hline Gender & -0.233 & 0.330 & 0.501 & 1 & 0.479 & 0.792 \\
\hline Resection & -0.632 & 0.326 & 3.744 & 1 & 0.053 & 0.532 \\
\hline \multicolumn{7}{|c|}{ Incremental model: staging } \\
\hline Age & 0.014 & 0.015 & 0.797 & 1 & 0.372 & 1.014 \\
\hline Gender & -0.250 & 0.331 & 0.569 & 1 & 0.450 & 0.779 \\
\hline Stage I & -1.191 & 0.628 & 3.594 & 1 & 0.058 & 0.304 \\
\hline Stage ॥ & -0.529 & 0.318 & 2.762 & 1 & 0.097 & 0.589 \\
\hline Stage III + IV & 0.635 & 0.308 & 4.261 & 1 & 0.039 & 1.888 \\
\hline
\end{tabular}

$b$ regression coefficient, SE standard error of regression coefficient b. Wald Wald statistic (b/SE)2, Df degrees of freedom, Exp (B) hazard risk ratio

The values in italics denote statistical significance

Future work could also examine the role of Tumor M2-PK as a component of a diagnostic and prognostic panel in combination with other markers such as D-Dimer which are differentially expressed in pancreatic cancer [15].

\section{Conclusion}

In conclusion, this study has examined the role of Tumor M2-PK as a marker of prognosis in patients with pancreatic and peri-ampullary cancer. The findings show that a value in excess of $27 \mathrm{U} / \mathrm{mL}$ is associated with shortened survival.

\section{Additional file}

Additional file 1: The original dataset is provided as a supplementary file. (XLSX $21 \mathrm{~kb})$

\section{Acknowledgements}

We acknowledge the invaluable assistance of Dr. Philip Pemberton PhD, Senior Clinical Scientist at Central Manchester \& Manchester Children's University Hospitals NHS Foundation Trust with sample preparation.

\section{Funding}

The authors acknowledge the assistance of Schebo Biotech AG, Giessen, Germany, in undertaking measurement of Tumor M2-PK.
Availability of data and materials

The full study dataset supporting the conclusions of this article is included within the Additional file 1.

Authors' contributions

IB led the data collection, contributed to the execution of the study, and helped write the manuscript. MB analyzed the study data and co-wrote the paper. SS shared the data collection and helped to write the manuscript. AKS designed the study, co-wrote the paper, and is the guarantor for this study. All authors read and approved the final manuscript.

\section{Ethics approval and consent to participate}

The study was approved by the North West Regional Ethics Committee (reference number 10/H1014/86). All patients gave their written informed consent for participation.

\section{Consent for publication}

By giving written informed consent, all patients gave their approval for publication of the results of the study. There are no individually identifiable patient-level data.

Competing interests

The authors declare that they have no competing interests.

\section{Publisher's Note}

Springer Nature remains neutral with regard to jurisdictional claims in published maps and institutional affiliations. 
Received: 3 October 2017 Accepted: 6 March 2018

Published online: 14 March 2018

\section{References}

1. Mazurek S, Grimm H, Oehmke Weisse G, Teigelkamp S, Eigenbrodt E. Tumor M2-PK and glutaminolytic enzymes in the metabolic shift of tumor cells. Anticancer Res. 2000;20:5151-4.

2. Wu J, Hu L, Chen M, Cao W, Chen H, He T. Pyruvate kinase M2 overexpression and poor prognosis in solid tumors of digestive system: evidence from 16 cohort studies. Onco Targets Ther. 2016;9:4277-88.

3. Eigenbrodt E, Basenau D, Holthusen, Mazurek S, Fischer G. Quantification of tumor type M2 pyruvate kinase Tu M2-PK in human carcinomas. Anticancer Res. 1997;17:3153-6.

4. Hugo F, Fisher G, Eigenbrodt E. Quantitative detection of tumour M2-PK in serum and plasma. Anticancer Res. 1999;19:2753-7.

5. Oremek GM, Eigenbrodt E, Radle J, Zeuzem S, Seiffert UB. Value of the serum levels of the tumour marker Tu M2-PK in pancreatic cancer. Anticancer Res. 1997;17:3031-4

6. Gupta V, Bamezai RN. Human pyruvate kinase M2: a multifunctional protein. Protein Sci. 2010;19:2031-44.

7. Christofk HR, Vander Heiden MG, Harris MH, Ramanathan A, Gerszten RE, Wei $R$, et al. The M2 splice isoform of pyruvate kinase is important for cancer metabolism and tumour growth. Nature. 2008:452:230-3.

8. Mazurek S. Pyruvate kinase type M2: a key regulator of the metabolic budget system in tumor cells. Int J Biochem Cell Biol. 2011;43:969-80.

9. Azoitei N, Becher A, Steinestel K, Rouhi A, Diepold K, Genze F, et al. PKM2 promotes tumor angiogenesis by regulating HIF-1a through NF-KB activation. Mol Cancer. 2016;15:3.

10. Goonetilleke KS, Mason JM, Siriwardana P, King NK, France MW, Siriwardena AK. Diagnostic and prognostic value of tumor M2 pyruvate kinase in periampullary cancer. Pancreas. 2007;34:318Y324.

11. Kumar Y, Gurusamy K, Pamecha V, Davidson BR. Tumor M2-pyruvate kinase as tumor marker in exocrine pancreatic cancer a meta-analysis. Pancreas. 2007:35:114-9.

12. Joergensen MT, Heegaard NH, Schaffalitzky de Muckadell OB. Comparison of plasma tumor M2-PK and CA19-9 in pancreatic cancer. Pancreas. 2010;39:243-7.

13. Mohammad GH, Olde Damink SW, Malago M, Dhar DK, Pereira SP. Pyruvate kinase $\mathrm{M} 2$ and lactate dehydrogenase a are overexpressed in pancreatic cancer and correlate with poor outcome. PLoS One. 2016;11:e0151635.

14. Ogawa H, Nagano H, Konno M, Eguchi H, Koseki J, Kawamoto K, et al. The combination of the expression of hexokinase 2 and pyruvate kinase M2 is a prognostic marker in patients with pancreatic cancer. Mol Clin Oncol. 2015; 3:563-71.

15. Durczynski A, Skulimowski A, Hogendorf P, Szymanski D, Kumor A et.al. The concentration of D-dimers in portal blood positively correlates with overall survival in patients with non-resectable pancreatic cancer. World J Surg Oncol. 2017;16;15(1):223. https://doi.org/10.1186/s12957-017-1291-4.

\section{Submit your next manuscript to BioMed Central and we will help you at every step:}

- We accept pre-submission inquiries

- Our selector tool helps you to find the most relevant journal

- We provide round the clock customer support

- Convenient online submission

- Thorough peer review

- Inclusion in PubMed and all major indexing services

- Maximum visibility for your research

Submit your manuscript at www.biomedcentral.com/submit 